\title{
Research on Construction of Village Cadres Competency Model in Western China Based on Grounded Theory
}

\author{
LIU Hui ${ }^{1, a}$ \\ ${ }^{1}$ International Business School of Shaanxi Normal University, Xi'an, Shaanxi, 710062, China \\ aliuhui.ibs@snnu.edu.cn
}

Keywords: grounded theory; village cadres; competency

\begin{abstract}
The competency and accomplishment of village cadres determine the development status of a village to a great extent. Based on the research paradigm of the grounded theory, a village cadres competency model, including three dimensions, namely achievement motivation, individual influence and management leadership capacity, as well as 12 indicators, covering personal prestige, sense of achievement, strategic capability, wealth creating capability, communication skills, responsibility, decision-making capacity and so on was built in the paper through carrying out in-depth interviews with village cadres in western China and coding analyses on the interview data. Such research results can provide a scientific basis for village cadres training, excitation and other aspects, and are conducive to the construction of village cadres talent team in western China.
\end{abstract}

\section{Introduction}

The village-level democratic governance has experienced a history of more than 30 years in China since from the first "villager autonomy" practice at Hezhai Village, Pingnan, Yizhou, Guangxi in 1980. During this period, many village collectives turned up. They have been developing rapidly due to the prominent leadership capacity, personality charm and related characteristics of the village cadres. Tremendous changes have occurred on farmers' living standard and the villages' image. Specific to the status quo that the economic development level of rural areas in the vast western regions is considerably lagging behind than that in the central and eastern regions, that most of the villagers have to further improve the educational level since their thoughts are relatively closed, and innovation consciousness are weaker, the predominance function of village cadres becomes particularly important. Therefore, to study the competent characteristic elements of village cadres in western China is an indispensable research content to solve the issues concerning agriculture, rural areas and farmers in western China. Setting the village cadres of villages in Shaanxi Province as the research object, the paper established a village cadres competency model by adopting the grounded theory with the intention to provide a scientific theory basis for the construction of village cadres talent team.

\section{Review of competency theory}

In 1911, Taylor started the scientific management movement. The diversity study between general workers and outstanding workers by adopting the analytical method of "time-action" was deemed as the earliest research on competency. In 1973, David C. McClelland, a professor of Harvard University in the United States, published an essay titled Testing for Competence Rather Than Intelligence, in which the concept of "competency" was officially proposed for the first time, and marked the beginning of competency movement [1]. From then on, more and more scholars began to pay close attention on researches of competence. Boyatzis (1982) considered the competency as the collection of knowledge, qualities, motivation, self-image, skills and social role characteristics and other characteristic elements which lead to individual excellent performance on the operating post [2].Spencer (1993) believed that the competency is characteristic set closely associated with potential and excellent job performance, including five dimensions viz knowledge, skill, motivation, character and self concept [3]. Scholar Mirable (1997) [4], Sandberg (2000) [5], Wang Chongming (2001) [6] and Peng Jianfeng (2003) [7] put forward representative views from the perspective of their own. 
Although the concept of competency has not been unified by scholars at home and abroad, the characteristics of competency can be summarized from three aspects [8]: (1) The competency is closely associated with the operating post. Different operating posts have different requirements on competency; (2) The competency can predict job performance. High competency means higher job performance; (3) The competency is reflected on the individual's behavior which can be measured through observation.

The competency model is a collection of competent characteristic elements. Specifically, it refers to the sum of all elements--knowledge, ability, skill and attitude etc. of individuals with high job performance at a professional field or job. In recent years, scholars at home and abroad established competency models applicable to various fields, such as companies, government management organizations and public education sectors by adopting a variety of research methods such as expert meeting method, focused interview, team focused discussion, critical incident method, investigation method and working log method, which can effectively guide human resource management practice in different industrial fields. However, there are few researches on competency specific to village cadres who are special rural junior managers. Similar researches set college-graduate village officials as research objects. College-graduate village officials belong to a very limited special community among rural root-level cadres. They have strong homogeneity. The competency model has no universal applicability. In conclusion, the competency model specific to ordinary rural grassroots cadres has more practical significance and application value.

\section{Research approaches and process}

Research approaches. The competency of village cadres is closely associated with the job characteristics. It mainly refers to more persistent and potentially essential characteristics that can be presented by individual behaviors that village cadres should possess to take the job. Due to the particularity of village cadres' job--the job contents are extensive, complicated and trivial, not only covering conventional activities of village daily management, but also villagers contradictions, disputes and emergent problems, the work achievements can hardly be observed, measured, monitored and quantitatively assessed from ordinary job performance and performance assessment. Therefore, it is not easy to determine the average and high achievement control group before studying village cadres competency. The general behavioral event interview can hardly be adopted to build the competency model. Specific to this circumstance, grounded theory was adopted as the research paradigm in the paper. Grounded theory is a qualitative research approach to build a theory from bottom to top based on empirical documentation. Yuanfang (1997) believed that experimental evidence is the basis of grounded theory, but not its main characteristics. The primary purpose of grounded theory is to abstract, extract the new concepts and ideas through in-depth analysis of empirical documentation [9]. The researches of many scholars demonstrated that grounded theory is a scientific and effective qualitative research approach [10].

According to the research paradigm of grounded theory, the core contents of the research include acquisition and analysis of empirical documentation. Empirical documentation is mainly acquired by adopting focus interview method and focus groups interview. Data analysis is one of the most important part of researches on the grounded theory. The step is often referred to as "encoding". The connotation is to decompose the collected or translated data, identify the phenomena, conceptualize the phenomena, re-abstract the concept through the right way, and operationalize the main category and core category [11]. The encoding process includes open encoding, axial encoding and selective encoding. Open encoding is to disperse the original data, give a new conceptual label to coded phrases or sentences thus to realize the conceptualization of original data. The key point of open encoding is that the researcher shall keep an open, objective state of mind by suspension some other scholars' research conclusions and own opinions. Axial encoding is to explore the similarity, differences, structure, function, cause and effect, sequence and other logical connection among sections based on concept category of open encoding. 
Selective encoding is the most abstract process among the three encoding processes. Its main task is to further systematically handle the internal relation in the scope of axial encoding thus to effectively identify the core category, and supplement the process of category that not developed completely.

Research process. 1. Data collection. Intensive sampling was primarily adopted in the research, the biggest difference sampling as complementary. Interviews were performed on village officers or village secretaries in seven ordinary rural areas. The so called intensive sampling refers to select those cases with higher intensity and density at case interview. The interview objects shall satisfy the conditions of taking the job over three years (one term) with rich work experience, high prestige among villagers, good evaluation and so on. The Max. difference sampling method is to ensure that it can utmost cover all kinds of different situations to the most extent [12]. Consequently, besides satisfying the limited-term of intensive sampling, select village cadres with different age, background, education level and regional sources. And finally, according to the theoretical saturated principle to determine the number of samples--when no new important information provided, stop samples extraction.

Based on the principle of "focusing on open-ended questions", the issues designed for the interview mainly are to guide the village cadres to describe key actions of the daily work. STAR strategy was adopted in the interview to raise questions and make a detailed inquiry. That's to say if an interview object is required to describe a task or specific action or reaction under detailed work situation, what kind of consequence or experience will occur .

Main interview questions include: (1) Please describe the main aspects of your current job. (2) Please elaborate on how to solve the most difficult problems of your previous work? (3) Please illustrate an example of failure or feeling deep regret on associated with your work during your tenure. The cause of failure may be contributed from your decision-making errors or improper operating approach therefore, the difficulty can not be solved. Please describe the most impressive experience for you. (4) As for you experience being a village cadre for many years, what do you think are indispensable capabilities and qualities for a village cadre to take the job? Please set one or two examples to illustrate your point of view. (5) Are you satisfied with your performance in the past years? Please list the good and bad aspects. Please give me an example to illustrate the subjective and objective causes affecting your job performance. (6) What competence and characters are required or need to be improved to better finish the tasks of a village cadre? What are the main causes? The interview is based on the outline questions. In actual questions, further inquiry shall be made at any time according to extracted conceptual categories to explore the inner world of the surveyed object thus to understand the key behavior characteristics of village cadres.

There are six interview team members in total, including four doctors of management and two masters of human resource management. In order to receive good effects from the interview, professional interview skill trainings will be conducted on team members respectively, as well as multiple simulation drills around the interview outline. The actual interview includes two types. The first type is one-on-one in-depth interviews, requiring 50min. to $120 \mathrm{~min}$.. The interview team members will make commitment to the surveyed objects that their personal information will be kept strictly confidential. The interview results will only be utilized for academic research. Then following the principle of depth interview skills, guide and encourage each respondent to describe details and real experience. The whole interview process will be recorded after obtaining the consent of the surveyed objects. All audio files will be transformed and systemized after the interview to complete interview transcription. The other type is to carry out a focused group interview relying on the resource of village cadres training class organized by Northwest Agriculture \& Forestry University. Two small sized village cadres seminars were organized. 30 interview samples were acquired in total. Four of them were removed since they are not in line with the requirements. 26 effective ones were remained, including two from focused group interview (four interview objects) and 18 individual depth interview samples. 
2. Data analysis. Based on the research paradigm of the grounded theory, the original data were divided into three steps for analysis, successively open encoding, axial encoding and selective encoding.

(1) Open encoding. To login step by step is required for words, sentences and paragraphs of original data, namely applying conceptual label for concept words or fragments of information. During the actual operation process, such conceptual labels can be distinct characteristic words that used by the surveyed object, and can be terms and phrases refined and abstracted through in-depth analysis. The objectives of the phase is to identify phenomena, define the concept and explore the category, namely to handle convergent issues. Specific operation steps are as following: First of all, conceptualize the label. Step I: Mark "ax" after every sentence with substantive meaning among the interview contents in the left column of interview data record as the mark of phenomenon definition; step II: Complete open encoding at the right column: (1) Extract the phrases or sentences marked as "ax". Concentrate the interview data contents to "initial concept"; (2) Perform classifying and merging for "initial concept". Take "aay" serial coding with the same or similar nature of concept labels. Thereof, "aay" will extract the expression of the same or similar defined concept to complete the process of open encoding. 141 initial concepts and 60 concepts will be obtained eventually by pasting a label and then conceptual extract. Secondly, perform categorization. The process of refining and summarizing in original interview data is categorization. The process needs multiple times of repeat investigation to make sure to accurately reflect the nature of the interview data. Denominate the categories and concepts according to diversification principle. Some are directly extracted from the interview transcription directly based on relevant literature data. Some are put forward after discussion with experts. After further classification and consolidation for 60 concepts, take "Az" to indicate category which can delegate the former concept and extract 12 categories, presenting in "A1"--"A12" respectively. They are: Motivation, seizing opportunities, wealth creating capability, organizing ability, persuasion, responsibility, heat insulation network, decision-making capacity, sense of achievement, strategic performance, coordination and communication skills. (see Table 1)

(2) Axial encoding. Through the open encoding at the first phase, 12 almost independent categories will be obtained. Next, it is necessary to further discuss the relationship between category and the category through axial encoding phase. Axial encoding refers to utilizing the typical model of "causality conditions $\rightarrow$ phenomena $\rightarrow$ pulse $\rightarrow$ interface $\quad$ conditions $\rightarrow$ action/interaction strategy $\rightarrow$ result" to link each category from the obtained open encoding to detect and establish the potential logical relationship among the categories. In short, the "main category" and "deputy category" will be obtained for the deeper exploration thus to separate category hierarchy. The paradigm model is an important analysis tool for grounded theory. The core idea is to help the researcher to further identify and master the category by utilizing specific time conditions, evolutionary skeleton and action strategies in the event as well as the eventual consequences. As shown in the Figure 1, 2 and 3 below, three major categories will be obtained by utilizing the model research tools. Figure 1 is constituted up by four categories, namely responsibility, motivation, seizing opportunities, sense of achievement, and 13 concepts, viz the sense of honor, sense of satisfaction, seizing the opportunity, unwilling to lag behind, dedication, never acknowledge defeat, go all out, encourage for exploitation, enterprising, relationship regulation, the sense of mission, be ambitious of success, to be a person with high aspirations and determination.

Table 1. Categorization of open encoding

\begin{tabular}{ll}
\hline Category & Concept \\
\hline A1 Motivation & $\begin{array}{l}\text { aa1 Encourage for exploitation; aa4 Despite the difficulties; aa8 Unwilling to lag } \\
\text { behind; aa43 Willingness; aa5 Gumption; } \\
\text { aa7 Fortitude; aa30 Go all out; aa6 Acknowledge defeat; aa40 Be ambitious of } \\
\text { success }\end{array}$ \\
$\begin{array}{l}\text { a2 Seizing opportunities; aa18 To be a person with high aspirations and } \\
\text { opportunities }\end{array}$ & $\begin{array}{l}\text { determination; aa48 Adjust measures to differing conditions; aa54 Summarize } \\
\text { experiences }\end{array}$ \\
aa3 Attract foreign businesses and investment; aa55 economic hotshots; aa45 \\
A3 Wealth creating
\end{tabular}


capability

A4 Organizational capability

A5 Persuasion

A6 Responsibility

A7 Personal prestige

A8 Decision-making ability

A9 Sense of achievement

A10 Strategy

A11 Coordination competence

A12 Communicative competence aa9 Skills to achieve prosperity; aa17 open-minded; aa49 Spirit of innovation

aa10 Mobilize the masses; aa26 Know how to make proper use of personnel; aa24

Arouse the enthusiasm of villagers; aa 28 Be good at motivating

aa46 Encourage participation; aa23 Scientific management; aa16 Rallying point;

aa27 Team work

aa11 Persuade through reasoning; aa12 Earnest instructions; aa13

Inspiring

aa14 Wholeheartedly for the people; aa22 Sense of mission; aa34

Self-sacrifice; aa42 Dare to be responsible; aa31 dedication

aa36 treat equally without discrimination; aa39 just and equitable;

aa41 self-discipline; aa44 believable; aa37 Reward and

punishment aa35 Integrity; aa15 Good mass base

aa47 Make a prompt decision; aa50 Grasp the overall situation;

aa25 Extensively consultation; aa53 Consciousness of risk

aa51 Adventurous; aa19 Enthusiasm for thoughts

aa33 Sense of honor; aa20 Sense of satisfaction; aa21 Dedication

aa29 Common sense

aa32 Good at communication; aa59 Relationship regulation; aa38

Dispute resolution

aa56 Good at communication; aa57 Active Listener; aa58 Transposition

consideration

The definition of the main category reflects village cadres with entrepreneur spirit and strong sense of responsibility. It can analyze the influencing factors of rural development consciously, put forward solution with stronger pertinence; be good at regulating various relationships, grasp the key opportunity to achieve the goal effectively; actively adjust the mentality to find the countermeasures to solve the problem with all the efforts. Such village cadres have high sense of mission and honor. They are particularly ambitious for success and being recognized. Consequently, the main category is originally defined as "achievement motivation". Figure 2 is constituted by 4 categories, namely strategic performance, persuasion, coordination skills and personal prestige, as well as 13 concepts as appeal, dedication, dispute resolution, good mass base, prosperity achieving capability, justice and equity, mobilizing the masses, arousing the enthusiasm of the villagers, credit, aggressive, self-discipline, responsibility, wholeheartedly for the people. The definition reflects that village cadres can efficiently integrate resources, fully mobilize the enthusiasm of the villagers, and make the villagers to cooperate them while leading the villagers to develop rural economy; while dealing with daily issues, they shall be good at relationship coordination, dealing with contradictions, insist on the principle of fair, just and responsibility; the village cadres shall be strict to discipline, honest and devote themselves to the public interests. Such village cadres have good mass basis and strong personal prestige and appeal. Consequently, the main category is originally defined as "individual influence". Figure 3 is constituted up by four categories, namely communication ability, organization ability, wealth creating capability, decision-making ability, and 13 concepts, including scientific management, economic development consciousness, experiences summarizing, open-minded, team work, attracting foreign businesses and investment, transposition consideration, solicit opinions from all sides, integrity, common sense, good at motivating, unifying the masses and risk awareness. The definition reflects that the village cadres have excellent awareness of development, open-minded and being able to adjust measures to differing conditions. Before implementation of the new approaches, solicit opinions from the villagers extensively with risk prevention consciousness. Effectively mobilize and organize the masses to develop the established goal diligently. It indicates that village cadres, as rural grassroots managers, shall have certain management means. Consequently, the main category is originally defined as "Leadership management ability". 


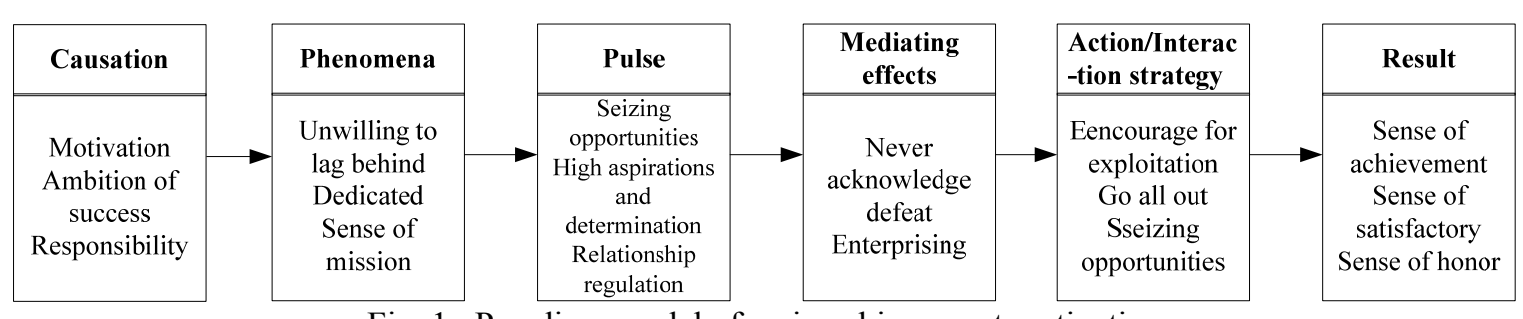

Fig. 1. Paradigm model of main achievement motivation

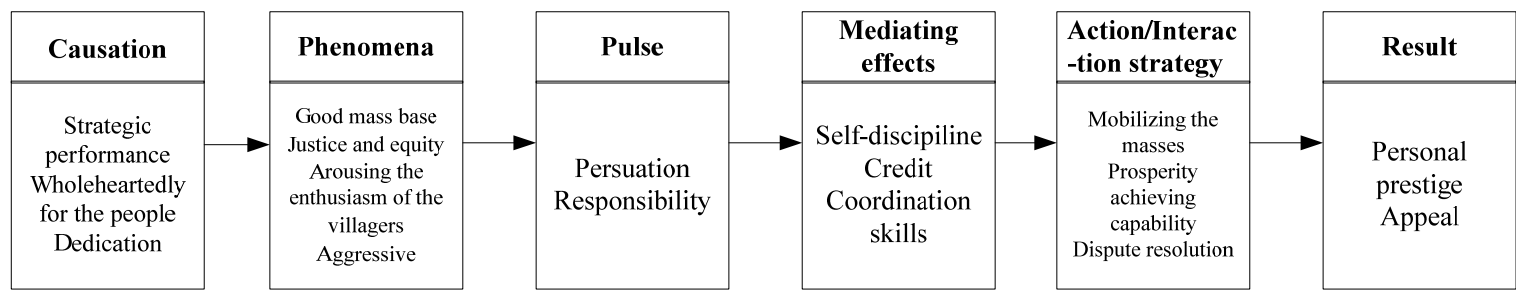

Fig. 2. Paradigm model of main category personal influence

\begin{tabular}{|c|c|c|c|c|c|}
\hline Causation & Phenomena & Pulse & $\begin{array}{c}\text { Mediating } \\
\text { effects }\end{array}$ & $\begin{array}{l}\text { Action/Interac } \\
\text {-tion strategy }\end{array}$ & Result \\
\hline $\begin{array}{c}\text { Awareness of } \\
\text { development } \\
\text { Open-minded } \\
\text { Experience }\end{array}$ & $\begin{array}{l}\text { Attract foreign } \\
\text { businesses and } \\
\text { investment } \\
\text { Extensively } \\
\text { consultation } \\
\text { Common sense }\end{array}$ & $\begin{array}{l}\text { Organization } \\
\text { ability } \\
\text { Unifying the } \\
\text { masses } \\
\text { Risk awareness } \\
\text { Good at } \\
\text { motivating }\end{array}$ & $\begin{array}{c}\text { Integrity } \\
\text { Communication } \\
\text { ability } \\
\text { Wealth creating } \\
\text { capability }\end{array}$ & $\begin{array}{c}\text { Transposition } \\
\text { Consideration } \\
\text { Team work } \\
\text { Experiences } \\
\text { summarizing }\end{array}$ & $\begin{array}{c}\text { Scientific } \\
\text { management } \\
\text { Transposition } \\
\text { consideration } \\
\text { Organizing } \\
\text { capacity }\end{array}$ \\
\hline
\end{tabular}

Fig. 3. Paradigm model of main category management leadership

(3) Selective encoding. Axial encoding can simplify and integrate the original complex data. In addition, it can establish the foundation for subsequent selective encoding. Selective encoding is for further information mining. The main objective is to detect the core category from the main category, and further verify the correlation between core category and other main categories. Selective encoding is to eventually develop a meaningful new theory framework through "storyline". Through continuously in-depth analysis on 12 subcategories, namely wealth creating capability, upward mobility, communication skills, seizing opportunities, coordination skills, strategic performance, personal prestige, persuasion, sense of achievement, organizational capability, responsibility and decision-making capacity, as well as further investigation on management leadership capacity, individual influence and achievement motivation, the writer determines "village cadres competence characteristics" as the core category to lead all the other categories. Surrounding the core category "storyline", it can be summarized as: with responsibility and upward mobility, not afraid of difficulties, willingness, adventurous, open-minded, with innovative spirit and consciousness of economic development. They have innovative spirit and consciousness of economic development, as well as good at adjusting measures to differing conditions as well as mastering the opportunity; being able to ponder the problems, good at communicating with the villagers, exclude the difficulty and anxiety for villages. They are integrity, faithful, treat everybody equally without discrimination. Therefore, they have good mass base. They have high prestige in the villager and become credible leader of villagers to create prosperity.

\section{Conclusion and expectation}

The research sets Shaanxi country as an example. Village cadres competency model is to establish village cadres competency model through in-depth interview and encoding analysis of interview data. Village cadres competency model includes three dimensions and 12-indicator multilayered structure. Three dimensions are achievement motivation, individual influence and management leadership respectively. Among them, achievement motivation is the primitive force for village cadres to drive rural development, including upward mobility, seizing opportunities, sense of achievement and responsibility; management leadership capacity is the basic condition of village cadres competence, including four indicators, namely organization capacity, decision-making capacity, communication 
skills and wealth creating capability; individual influence is the key element to carry out jobs smoothly, including strategy, persuasion, personal prestige and coordination ability.

At present, China is under the critical period to accelerate agricultural development and promote construction of socialism new countryside. The practice indicated that their own ability of village cadres will directly affect harmonious development of the rural economy and society. Construction of village cadres competency model can provide scientific basis for rural grassroots cadres selection, training, excitation and so on. In addition, it is conducive to the construction of village cadres talent team. Due to the particularity of village cadres, the research paradigm of grounded theory was adopted in the research to perform exploratory research. Subsequent researches need to expand the sample source. In-depth analysis and empirical test can be conducted through quantitive data analysis to make up the disadvantage of qualitative research.

\section{References}

[1] McClelland, D.C Testing for Competence Rather than for Intelligence [J]. American Psychologist, 1973, 28(1):1-14.

[2] Boyatzis, R E. The competence manager: A model for effective performance [M]. New York: John Wiley \& Sons, Inc, 1982.

[3] Spencer L M, and Spencer, S M. Competence at work: Models for superior performance [M]. New York: John Wiley \& Sons, Inc, 1993.(17): 12-14.

[4] Mirabile R J. Everything you wanted to know about competency modeling [J]. Training \& Development, 1997, 51(8):73-77.

[5] Sandberg J. Understanding human competence at work: an interpretative approach [J]. Academy of Management Journal, 2002.,43(1): 9-25.

[6] WANG Chongming Analysis of Characteristics of Management Competency: Structural Equation Model Test [J]. Psychological Science, 2002 (5), 513-516.

[7] PENG Jianfeng, RAO Zheng Competency Based HRM [M]. Beijing: China Renmin University Press, 2003

[8] LIU Zewen Competency Modeling--Instance Analysis of Talents Selection and Assessment [M]. Beijing: Science Press, 2009

[9] YUAN Fang, WANG Hansheng Social Research Methods Course [M]. Beijing: Peking University Press, 1997

[10] Hammersley M. The Dilemma of Qualitative Method: Herbert Blumer and the Chicago [M].Tradition London and New York: Routledge, 1989.

[11] LI Zhigang Application Analysis of Grounded Theory on Scientific Research [M]. Oriental BBS, 2007, (4): 90-94.

[12] CHEN Xiangming Qualitative Research Approach and Social Science Research [M]. Beijing: Education and Science Press, 2000. 